\title{
Pemanfaatan Mobile Health Guna Mendukung Edukasi Kesehatan Reproduksi Keluarga Di Dusun Mejing Lor, Ambarketawang, Gamping, Sleman
}

Kegiatan ini memperkenalkan aplikasi reproduksi berbasis Android untuk meningkatkan pengetahuan tentang kesehatan reproduksi pada remaja dan keluarga di Dusun Mejing Lor, Ambarketawang, Gamping

\author{
Laili Rahmatul Ilmi ${ }^{1 *}$, Dedy Sulistiawan ${ }^{2}$, Kori Puspita Ningsih ${ }^{3}$, Ida Nur Santi ${ }^{4}$, Sis Wuryanto ${ }^{5}$, \\ Yuniarti Modiasti Tuga ${ }^{6}$, Hanung Banar ${ }^{7}$. \\ ${ }^{1}$ Universitas Jenderal Achmad Yani Yogyakarta \\ ${ }^{2}$ Universitas Achmad Dahlan Yogyakarta \\ 3,4,5,6,7 Universitas Jenderal Achmad Yani Yogyakarta \\ *Korespondensi: lailiilmi@gmail.com
}

\begin{abstract}
ABSTRAK. Era digitalisasi 4.0 menuntut masyarakat melek teknologi salah satunya dibidang kesehatan. Pemanfaatan aplikasi bidang kesehatan tidak hanya memberikan informasi kesehatan namun menstimulasi kesadaran masyarakat untuk hidup sehat. Banyak berkembang aplikasi kesehatan yang diakses secara gratis melalui mobile. Tujuan pengabdian masyarakat mengedukasi pemanfaatan aplikasi mobile health (M-health) yang tersedia di Android atau IOS mendukung kesadaran masyarakat untuk bisa mengikuti pola hidup sehat dan memiliki kemudahan akses informasi kesehatan. Aplikasi $m$-health tentang kesehatan reproduksi untuk remaja ataupun keluarga, masyarakat tidak perlu malu dan ragu untuk mendapatkan informasi perihal kesehatan organ vital reproduksi, edukasi perawatan dan informasi pra-post pernikahan dan lain halnya. Sasarannya adalah ibu PKK Dawis Kenikir, remaja di dusun Mejing Lor, RT 04, kel. Ambarketawang, Kec. Gamping, Kabupaten Sleman. Kegiatan ini diselenggarakan secara langsung atau luring dengan tetap mematuhi protokol kesehatan dimasa Pandemi Covid-19. Pelaksanaan kegiatan ini pada tahap pertama melakukan koordinasi dengan RT 04 Mejing Lor, Ambarketawang, Gamping, Sleman, tahap kedua penyampaian materi secara daring dan luring. bagi peserta yang tidak hadir dan luring bagi yang berkenan dengan batasan peserta 10 orang dan wajib disesuaikan dengan protocol kesehatan ketat. Pemateri pertama membahas pentingnya kesehatan reprodoksi dan pemateri kedua tentang pemanfaatan aplikasi mhealth, dilanjutkan diskusi dengan peserta.
\end{abstract}

Kata kunci: Aplikasi, Edukasi, m-health, Kesehatan Reproduksi

ABSTRACT. The era of digitalization 4.0 requires a technologically literate society, one of which is in the field of health. The Utilization of health applications not only provides health information but stimulates public awareness for healthy living. Mostly, kinds of apps for health are available on Android or IOS The goal of community service is to educate the use of mobile health applications (M-health) available on Android or iOS to support public awareness to be able to follow a healthy lifestyle and have easy access to health information. The aims of this event are to educate the use of mobile health applications (M-health) available on Android or iOS to support public awareness to be able to follow a healthy lifestyle and have easy access to health information. M-health application about reproductive health for adolescents or families, the public should not be ashamed and hesitant to get information about the health of reproductive vital organs, care education and pre-post marriage information and others. The target was PKK Dawis Kenikir, a teenager in the hamlet of Mejing Lor, RT 04, Ambarketawang, Kec. Gamping, Sleman Regency. This activity is held directly or offline while still complying with health protocols during the Covid-19 Pandemic. The implementation of this activity in the first stage coordinates with RT 04 Mejing Lor, Ambarketawang, Gamping, Sleman, the second stage of the delivery of material online and offline. for participants who are not present and offline for those who are pleased with the limit of 10 participants and must be adjusted to strict health protocols. The first speaker discussed the importance of reproductive health and the second speaker on the utilization of mhealth applications, continued discussion with participants.

Keywords: Applications, Education, m-health, Reproductive Health

\section{PENDAHULUAN}

Pada masa digitalisasi semakin banyak tuntutan di segala sektor salah satunya bidang kesehatan untuk memanfaatkan system informasi dan teknologi kesehatan. Banyak berkembang aplikasi kesehatan yang dapat diakses secara gratis melalui mobile atau telepon pintar oleh masyarakat. Tujuan dari pemanfaatan aplikasi mobile health (M-health) 
guna mendukung kesadaran masyarakat untuk bisa mengikuti pola hidup sehat dan memiliki kemudahan akses informasi kesehatan (Gonsalves et al., 2015).

Aplikasi m-health memberikan berbagai informasi yang dibutuhkan oleh masyarakat umum, tidak hanya informasi namun kemudahan akses. Salah satu contohnya yaitu pemanfaatan aplikasi kesehatan reproduksi baik untuk remaja ataupun keluarga, tentunya dengan aplikasi tersebut masyarakat tidak perlu malu dan ragu untuk mendapatkan informasi perihal kesehatan organ vital reproduksi, edukasi perawatan dan informasi pra-post pernikahan dan lain halnya(Rokicki \& Fink, 2017).

Beberapa penelitian sebelumnya menjelaskan bahwa pemanfaatan aplikasi berbasis mobil akan memberikan dampak yang banyak, tidak hanya kemudahan akses(Nelson et al., 2019), namun bisa meningkatkan kesadaran masyarakat untuk berpola hidup sehat demi kesehatan alat reproduksi untuk keberlanjutan kehidupan(Tool et al., 2015)(Schnall et al., 2017). Karena kehidupan seksual dikalangan masyarakat masing ada yang menggap tabu teruatma di negara dengan tingkat perekonomian rendah dan negara berkembang, namun dengan adanya aplikasi kesehatan reproduksi remaja dan keluarga dapat dijadikan ajang komunikasi antara remaja dan keluarga untuk lebih peduli akan kesehatan tersebut(Ippoliti \& L'Engle, 2017)(Gilmore et al., 2017).

Berdasarkan hasil wawancara dengan Ibu RT 04 Mejing Lor, bahwasannya banyak warga mejing lor kurang aktif dalam kegiatan posyandu, kurang terpaparnya informasi terkait kesehatan reproduksi remaja dan keluarga. Oleh sebab itu, diperlukan sosialisasi yang membahas pemanfaatan aplikasi $m$ health guna mendukung edukasi kesehatan reproduksi remaja dan keluarga. Kegiatan ini akan diselenggarakan secara langsung atau luring dengan tetap mematuhi protocol kesehatan dimasa Pandemi Covid-19.

Tujuan kegiatan pengabdian kepada masyarakat ini adalah untuk memberikan gambaran kepada masyarakat akan pentingnya pemanfaatan aplikasi kesehatan berbasis mobile serta latihan mengguunakna aplikasi guna mendukung edukasi kesehatan reproduksi keluarga. Pada kegiatan ini memiliki beberapa tujuan khusus yaitu definisi secara harfiah aplikasi kesehatan berbasis $m$ health, menjelaskan mengenai jenis-jenis aplikasi reproduksi, menjelaskan mengenai kesehatan reproduksi remaja dan keluarga permasalahan kesehatan masyarakat

\section{METODE}

Kegiatan ini, akan dilakukan kegiatan pengabdian melalui metode pelatihan dan penyuluhan langsung kepada Ibu-ibu PKK dasawisma kenikir yang bertempat tinggal di Wilayah Mejing Lor, RT 04, Kelurahan Ambarketawang, Kecamatan Gamping, Kabupaten Sleman dengan metode ceramah dan diskusi. Alat dan bahan yang digunakan yaitu Komputer atau Notebook, LCD, Sound system, Kamera dan video. Prosedur pelaksanaan kegiatan. Pada kegiatan ini terbagi menjadi 3 kegiatan meliputi:

\section{Tahap Persiapan}

Tahap pertama yaitu persiapan yang dilakukan adalah studi pendahuluan dengan wawancara kepada Ketua RT 04 Dusun Ambarketawang saat ada kegiatan rutin dengan Ibu-ibu paguyuban dasawisma kenikir yang bertempat tinggal di Wilayah Mejing Lor, RT 04 dilaksanakan secara luring dengan memperhatikan protocol covid. Kegiatan ini diselenggarakan di Kelurahan Ambarketawang, Kecamatan Gamping, Kabupaten Sleman. Setelah itu, tim mulai merumuskan masalah kemudian menyusun proposal pengabdian kepada masyarakat. Kegiatan selanjutnya adalah menyusun materi untuk kegiatan penyuluhan.

\section{Tahap Pelaksanaan}

Tahap kedua kegiatan pengabdian diawali dengan menyampaikam materi yang dihadiri oleh ibu-ibu paguyuban dasawisma kenikir yang berlokasi di kediaman ibu RT 04 Dusun Ambarketawang. Para Pemateri dan mahasiswa menggunakan APD dan jumlah peserta dibatasi maksimal 10 orang terdiri dari 2 pemateri, 3 mahasiswa, 8 peserta, sedangkan peserta daring berjumlah 14 .

\section{Tanggal kegiatan}

Kegiatan ini dilaksanakan pada tanggal 28-29 Desember 2020. 


\section{HASIL DAN PEMBAHASAN}

Kegiatan ini dilaksanakan sebanyak tiga tahap pelaksanaan yang di lakukan pada Dusun Mejing Lor, Kel. Ambarketawang, Kec. Gamping, Kab. Sleman.yang dihadiri oleh 10 Dawis Kenikir secara luring dan 14 orang secara daring. Kegiatan pengabdian merupakan hasil pendampingan dan penyuluhan kesehatan reproduksi keluarga dan pemanfaatan $m$-health kesehatan reproduksi di Dusun Mejing Lor, Kel. Ambarketawang, Kec. Gamping, Kab. Sleman.

Adapun kegiatan pengabdian kepada masyarakat tahap pertama adalah berupa apersepsi awal dengan ibu-ibu dasawisma kenikir didampingi oleh ketua RT 04 RW 02 terkait wacana dan kegiatan apa yang ingin didiskusikan pada kegiatan Pengabdian ini, tahap kedua adalah pelaksanaan berupa edukasi perihal mengenai kesehatan reproduksi remaja dan keluarga dan pemanfaatan $m$-health yang dilaksanakan pada hari Jumat 29 Desember 2020, di kediaman Bapak Agus Sarjana, SH., Selaku ketua RT 04 pada pukul 15.00-17.00 WIB. Pada tahapan ini meliputi pretest untuk mengetahui tingkat pemahaman para peserta yang ibbu dasawisma kenikir. Kegiatan selanjutnya adalah pemberian pendidikan kesehatan reproduksi remaja dan keluarga dan pemanfaatan $m$ health. Materi pertama disamaikan oleh Bapak Dedik Sulistyawan, SKM menyampaikan definisi, tujuan, manfaat, prosedur atau tata cara menjaga kesehatan reproduksi dan dampaknya. Materi kedua adalah perihal pemanfaatan aplikasi kesehatan berbasis mobile (m-health) yang berkaitan dengan kesehatan reproduksi remaja dan keluarga. Pada saat penyampaian materi, peserta sangat antusias, kooperatif dan aktif ketika sesi tanya jawab. Setelah sesi ini berakhir dilanjutkan dengan sesi post test.

Sesi ketiga yaitu penyerahan APD dan sumbangan alat kesehatan yang dapat diamanfaatkan bagi kegiatan rutin di dasawisma kenikir. Hasil dari pre dan post test yang dilakukan kepada peserta menunjukkan adanya peningkatan. Hasil disajikan dalam grafik dibawah ini.
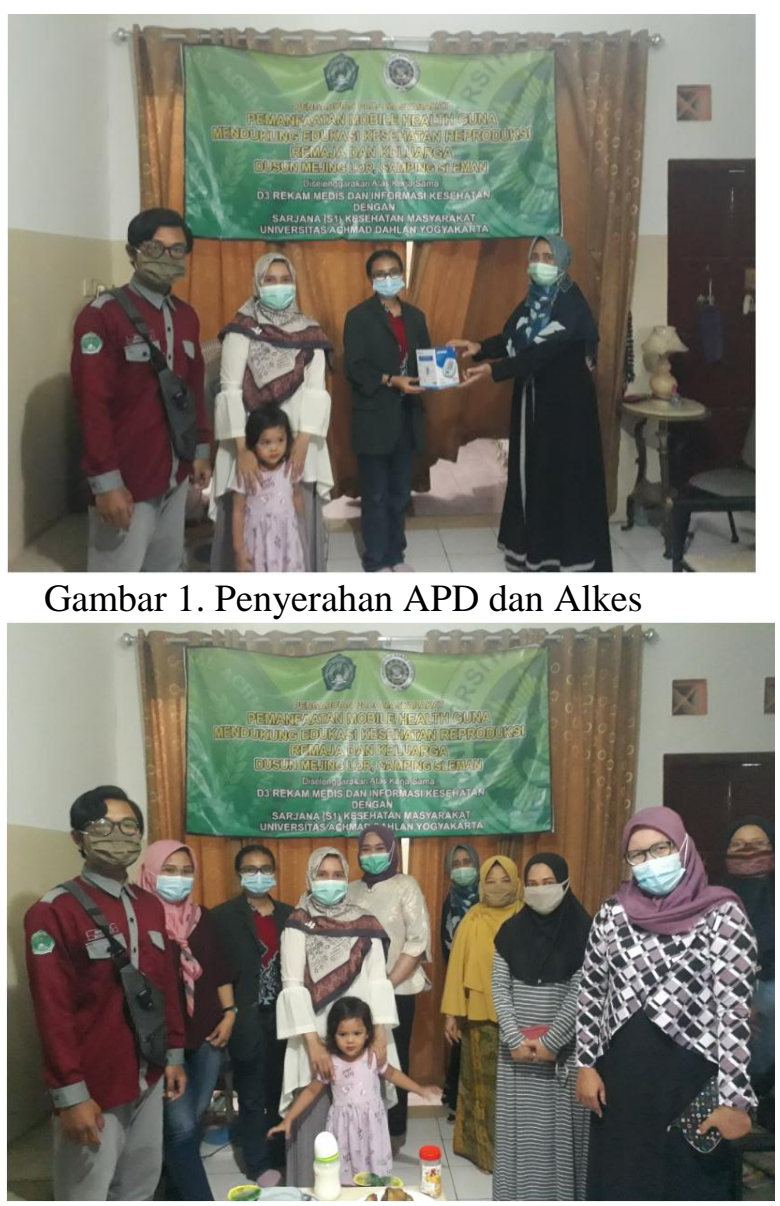

Gambar 2. Paska kegiatan edukasi dan pendampingan

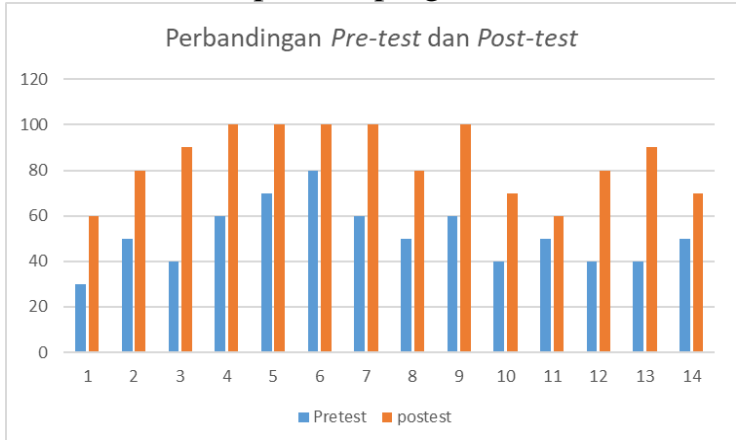

Gambar 3. Hasil perbandingan Pre-test dan Post Test

Berdasarkan gambar diatas, menunjukkan bahwa ada perbandingan pengetahuan responden sebelum dan sesudah diberikan edukasi perihal pendidikan kesehatan reproduksi remaja dan keluarga dan pemanfaatan m-health. Hasil tersebut menunjukkan bahwa hasil post test ada kenaikan. 
Hasil rekapitulasi pengetahuan kesehatan remaja dan keluarga serta pemanfaatan $\mathrm{m}$ health.

Tabel 1. Rekapitulasi hasil pre-test dan

\begin{tabular}{|c|c|c|c|c|c|}
\hline & \multicolumn{5}{|c|}{ post-test } \\
\hline No & Nilai & pretest & $\%$ & post test & $\%$ \\
\hline 1 & $\begin{array}{l}>56 \\
\text { (kurang) }\end{array}$ & 9 & $64 \%$ & 0 & \\
\hline 2 & $\begin{array}{l}56-75 \\
\text { (cukup) }\end{array}$ & 4 & $29 \%$ & 4 & $29 \%$ \\
\hline 3 & $\begin{array}{l}76- \\
100 \text { (baik) }\end{array}$ & 1 & $7 \%$ & 10 & $71 \%$ \\
\hline
\end{tabular}

Berdasarkan hasil rekapitulasi pada table 5.1 diatas menunjukkan bahwa pemberian edukasi kesehatan reproduksi remaja dan keluarga serta pemanfaatan aplikasi m-health yang telah dilaksanakan memberikan pengaruh positif terhadap pengatahuan ibu dan remaja dasawisma kenikir RT 04 Mejing Lor, Gamping, Sleman. Hasil pretest diatas menunjukkan bahwa tingkat pengetahuan kurang dengan prosentasi dibawah $(>64 \%)$ dengan nilai 9 peserta, tingkat pengetahuan cukup (29\%) sebanyak 4 peserta dan kategori baik $(7 \%)$.

Hasil ini sejalan dengan penelitian yang dilakukan oleh (Mahmood et al., 2019) bahwa pemberikan stimulus dengan informasi kesehatan dengan memanfaatkan system informasi kesehatan. Menurut (Awasighe Francis et al., 2019) bahwasannya pemanfaatan teknologi informasi bidang kesehatan repproduksi bagi remaja dan dewasa berperan penting mendukung peningkatan pengetahuan seksual demi peningkatan mutu kesehatan masyarakat.

Rencana tindak lanjut dari kegiatan ini adalah untuk mengadakan kembali kegiatan serupa perihal peningkatan edukasi bidang kesehatan dalam peningkatan derajat kesehatan di masyarakat serta mendukung kegiatan preventif demi mencapai derajat kesehatan bersama. Kesuksesan kegiatan ini karena semua peserta sangat antusias dalam mengikuti kegiatan sosialisasi dan aktif berdiskusi pada kegiatan tersebut. Factor yang kurang mendukung kegiatan ini adalah keterbatasan peserta karena kondisi pandemic, namun secara keseluruhan peserta sangat antusias mengikuti kegiatan ini.

\section{SIMPULAN}

Kegiatan pengabdian kepada masyarakat yang telah dilakukan mendapatkan hasil sesuai tujuan yang diharapkan, hal ini dibuktikan melalui hasil evaluasi post test yang meningkat, serta para peserta menjadi lebih baik termotivasi untuk menjaga kesehatan dan teredukasi untuk bisa memanfaatkan aplikasi kesehatan berbasis mobile. Hasil kegiatan tersebut sejalan dengan beberapa penelitian sebelumnya bahwa pemberikan stimulus dengan informasi kesehatan dengan memanfaatkan system informasi kesehatan. reproduksi bagi remaja dan dewasa berperan penting mendukung peningkatan pengetahuan seksual demi peningkatan mutu kesehatan masyarakat Setelah pelaksaan tersebut Harapannya dengan adanya kegiatan ini, peserta lebih termotivasi dalam meningkatkan ilmu bidang kesehatan dan menambahkan wawasan dalam melek teknologi kesehatan

\section{UCAPAN TERIMAKASIH}

Terima kasih kepada Ketua RT 04, Mejing Lor, Ibu PKK Dasawisma Keninir, Kel. Ambarketawang, Kec Gamping Sleman. Terima kasiha kepada Prodi Kesehatan Masyarakat Universitas Jenderal Achmad Yani Yogyakatta dan Fakultas Kesehatan Universitas Jenderal Achmad Yani Yogyakarta.

\section{DAFTAR PUSTAKA}

Awasighe Francis, E., Veronica Chizoba, G., \& Adesola, O. (2019). Using Mobile Technology to Access Sexual and Reproductive Health Information and Services by Adolescent \& Young Persons: Findings from Nigeria. Universal Journal of Public Health, 7(2), 73-81. https://doi.org/10.13189/ujph.2019.070205

Gilmore, L. A., Klempel, M. C., Martin, C. K., Myers, C. A., Burton, J. H., Sutton, E. F., \& Redman, L. M. (2017). Personalized Mobile Health Intervention for Health and Weight Loss in Postpartum Women Receiving Women, Infants, and Children Benefit: 26(7), 719-727. https://doi.org/10.1089/jwh.2016.5947

Gonsalves, L., L'Engle, K. L., Tamrat, T., Plourde, K. F., Mangone, E. R., Agarwal, 
S., Say, L., \& Hindin, M. J. (2015). Adolescent/Youth Reproductive Mobile Access and Delivery Initiative for Love and Life Outcomes (ARMADILLO) Study: formative protocol for mHealth platform development and piloting. Reproductive Health, 12(1), 1-10. https://doi.org/10.1186/s12978-0150059-y

Ippoliti, N. B., \& L'Engle, K. (2017). Meet us on the phone: Mobile phone programs for adolescent sexual and reproductive health in low-to-middle income countries. Reproductive Health, 14(1), 1-8. https://doi.org/10.1186/s12978-0160276-z

Mahmood, A., Kedia, S., Wyant, D. K., Ahn, S. N., \& Bhuyan, S. S. (2019). Use of mobile health applications for healthpromoting behavior among individuals with chronic medical conditions. Digital Health, 5, 1-17. https://doi.org/10.1177/20552076198821 81

Nelson, E. C., Verhagen, T., Vollenbroekhutten, M., Noordzij, M. L., \& Nelson, E. C. (2019). Is Wearable Technology Becoming Part of Us? Developing and Validating a Measurement Scale for Wearable Technology Embodiment Corresponding Author: 7, 1-12. https://doi.org/10.2196/12771

Rokicki, S., \& Fink, G. (2017). Assessing the reach and effectiveness of mHealth: Evidence from a reproductive health program for adolescent girls in Ghana. BMC Public Health, 17(1), 1-14. https://doi.org/10.1186/s12889-0174939-7

Schnall, R., Rojas, M., Bakken, S., Iii, W. B., Carballo-, A., Carry, M., Gelaude, D., \& Mosley, J. P. (2017). A user-centered model for designing consumer mobile health application (apps). J Biomed Inform, 60, 243-251. https://doi.org/10.1016/j.jbi.2016.02.002. A

Tool, A. S. A., Integrated, F. O. R., Strengthening, S., Sexual, I. N., \& Programming, R. H. (2015). mHealth as a tool for integrated systems strengthening in sexual and Implementation Experience (Issue June). 